\title{
Búnkeres del siglo XX: cicatrices patrimoniales
}

Alberto Atanasio Guisado | Universidad Nacional de Educación a Distancia (UNED)

Jorge Moya Muñoz | Dpto. de Expresión Gráfica Arquitectónica, Universidad de Sevilla

URL de la contribución <www.iaph.es/revistaph/index.php/revistaph/article/view/5035>

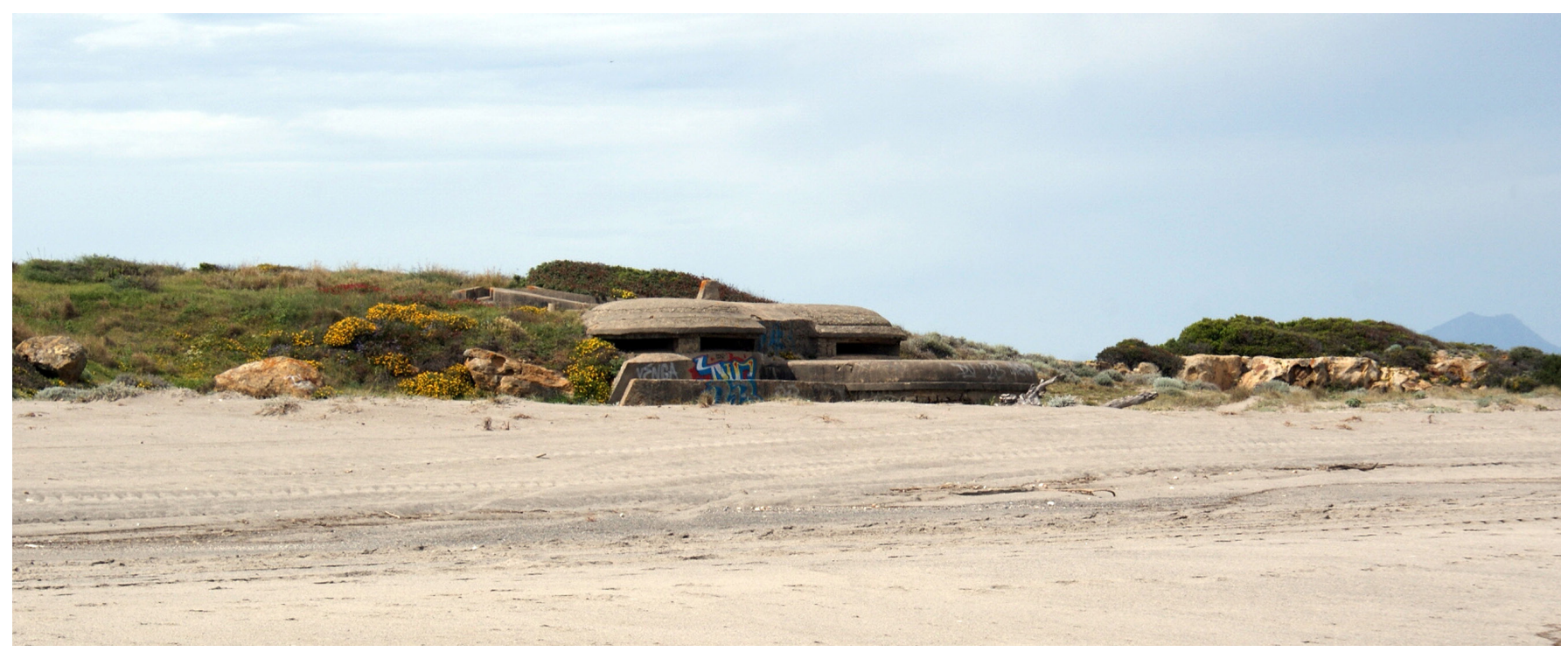

Búnker I.A.28 en Punta Mala, playa de San Roque, Cádiz | foto Alberto Atanasio Guisado y Jorge Moya Muñoz

Alrededor del mundo, muchos países, incluido España, fueron fortificados antes o durante la Segunda Mundial. Todos son por tanto contenedores de una "arqueología del búnker", concepto que autores como Paul Virilio (1994) comenzaron a desarrollar de forma extraordinariamente precoz.

No es escaso el soporte jurídico que arropa la consideración patrimonial de los fortines de la Guerra Civil o de la Segunda Guerra Mundial, tanto a nivel estatal, como a nivel autonómico en Andalucía. Acogidos bajo el paraguas del Plan Nacional de Arquitectura Defensiva (PNAD) o el Plan de Arquitectura Defensiva de Andalucía (PADA), ambos textos justifican el amparo jurídico de la totalidad de la arquitectura defensiva en base al Decreto de 1949 en el que todos los castillos de territorio nacional quedaron bajo resguardo legal. Posteriormente, la
Ley 16/1985 de Patrimonio Histórico Español declaró de Interés Cultural los bienes recogidos en el Decreto de 1949. La confusión terminológica arrastrada desde entonces acerca de qué era o dejaba de ser un castillo quedó resuelta con la definición de los Planes de Arquitectura Defensiva, que ampliaron su significado a "arquitectura defensiva" (PNAD) o "arquitectura militar" (PADA).

Sin embargo, a pesar de la existencia de ese régimen tutelar, lo cierto es que todavía recae sobre los fortines del siglo XX cierta pátina de desconfianza. ¿Por qué no son reconocidas estas extraordinarias construcciones?, se preguntaba Virilio hace ya cincuenta años (Virilio 1994, 11. Traducción de los autores).

La respuesta más inmediata guarda relación con la composición y materialidad de las propias obras, pequeñas, 
desnudas y de hormigón armado. No obstante, estos lugares comunes relativos al monumentalismo han sido hoy ampliamente sobrepasados, invalidando este argumento.

La realidad es algo más compleja, y queda vinculada a la memoria de esta fortificación, a su capacidad de simbolizar guerra y represión en un tiempo aún demasiado reciente. Esa significación es lo que hace a este patrimonio diferente a otros, caracterizándolo como un patrimonio incómodo. Es, de hecho, comprensible: los búnkeres representan objetos abominables desde su construcción y cualquier posible acción para su puesta en valor se enfrentará siempre a su pasado, al artefacto militar repulsivo ejecutado habitualmente por mano de obra represaliada.

A negative monument, a fearsome heritage (Cocroft y Scthofield 2009), discord value (Dolff-Bonekämper 2001); son términos acuñados para referirse y afrontar el legado material de conflictos o situaciones conflictivas que nos dejó el siglo XX. Para nosotros, el acercamiento más afortunado a esta incómoda realidad es el propuesto por John Beck, quien acude a Zygmunt Bauman y a su definición de ambivalencia como: "la posibilidad de asignar a un objeto o acontecimiento en más de una categoría" (cit. en Beck 2011, 83. Traducción de los autores). Señala Bauman, y concluye Beck, que esa incapacidad del lenguaje de delimitar el significado nos provoca un agudo malestar, al no ser capaces de obtener una denominación que no sea ambigua. "Para mí, el búnker es una especie de metáfora del sofocamiento, de la asfixia, de aquello que a la vez me horroriza y me fascina", declaraba Virilio aún en 2003 (Virilio y Lotringer 2003, 23).

Lo artificial y su integración en la naturaleza, la atracción por objetos originalmente repulsivos, la revelación de lo que quería mantenerse oculto, la significación de una arquitectura fabricada para matar... un agudo malestar, una profunda ambivalencia. La condición ambivalente del fortín es incuestionable y es precisamente esa condición lo que provoca repulsión y hechizo a un mismo tiempo.

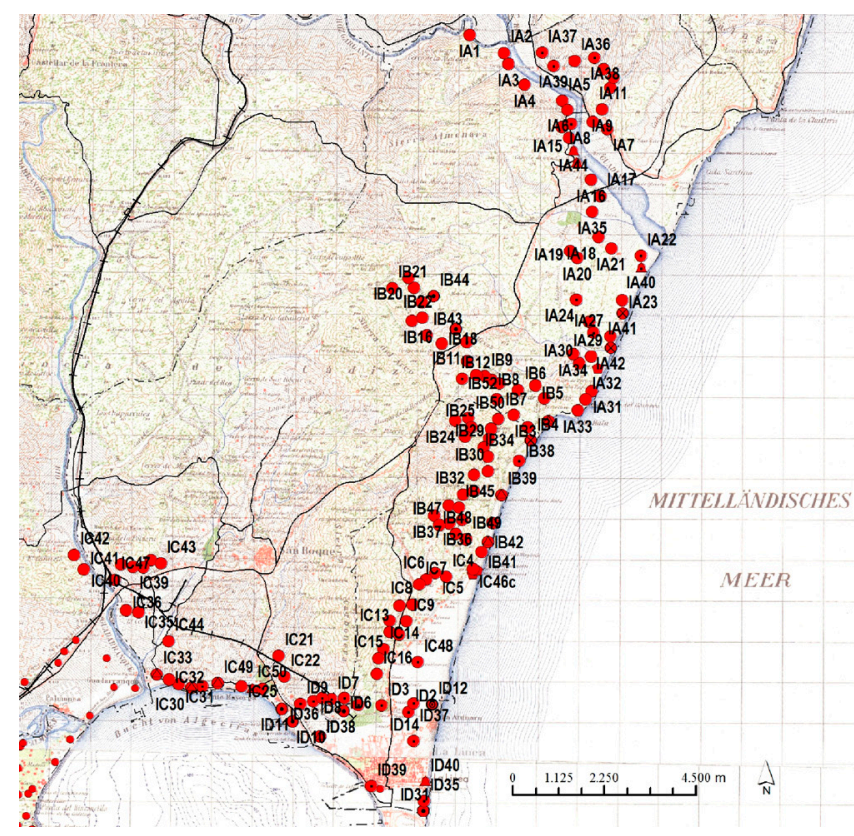

Sector de fortificación donde se encuadra el búnker I.A.28, desde el río Guadiaro al río Guadarranque | mapa Alberto Atanasio Guisado y Jorge Moya Muñoz

La serie fotográfica Campos de batalla, de María Bleda y José María Rosa, comprendía inicialmente veintiún dípticos, todos paisajes fotografiados entre 1994 y 1996 dentro del territorio nacional. En todas ellas aparece, además, una línea de texto que titula cada imagen. Es solo lugar y fecha, pero es lo que provoca la reacción del espectador: cada título señala una batalla, transformando el paisaje inocuo en un ejercicio de rememoración individual. La introducción del texto deviene en un enorme efecto evocador de la fotografía, relacionando un territorio inerme con el imaginario bélico de cada perceptor.

Campos de batalla inspiró a Iñaki Ábalos (2005)a proponer la voluntariosa idea de la "Red de Campos de Batalla". Pretendía ser una forma de dotar de significado a ciertos "paisajes desactivados" de la Península Ibérica: Bailén, Almansa, Sagunto, Roncesvalles, Trafalgar... Todas batallas importantes de la historia de España y todas de nuevo vívidas en nuestro imaginario gracias a Bleda y Rosa. ¿Podría proponerse, de un modo para- 
lelo, la Red de Sistemas Fortificados Contemporáneos? Campo de Gibraltar, Línea Pirineos, Frente de Madrid... Los fortines por sí mismos cuentan con un poder evocador suficiente. Esos mismos fortines, insertos en el paisaje, también. Frente a los campos de batalla, tendrían la capacidad de ejercer como elemento indicador de su propia naturaleza. El búnker habla por sí mismo, se auto-anuncia y nos ofrece su paisaje revelado. "Un lugar vacío sólo necesita ser designado por una señal para pasar a tener 'aura' de cara al turista" (Diller y Scofidio 1994, 28).

Sin embargo, no es suficiente si cada uno de los búnkeres es recogido de forma particular. Cada fortín pertenece a un conjunto de obras ejecutadas para defender un territorio. Su poder de evocación será mucho mayor si se presentan como sistema, como masa crítica. La dificultad estriba en cómo hacer notar esa condición cuantitativa y territorial de la mayoría de los sistemas fortificados; y el desafío es incluir esa masa crítica en el imaginario individual del perceptor del paisaje fortificado. Es esa cifra, el plano saturado de puntos, conexiones y carreteras, lo que hará comprender al visitante la magnitud de la transformación que se realizó o pretendía realizarse allí, bajo sus pies, y en todo el extenso territorio que le rodea.

"Aquí reside -afirmará G. Van den Abbeele- el secreto de la indestructibilidad del lugar: no es el espacio físico lo que importa sino su inscripción dentro de los sistemas de memoria cultural. El lugar puede ser destruido (...) pero no puede ser borrado como atracción turística a menos que sea borrado también de la memoria cultural" (cit. en Diller y Scofidio 1994).

\section{BIBLIOGRAFÍA}

- Ábalos, I. (ed.) (2005) Campos de batalla. Barcelona: Col-legi d'Arquitectes de Catalunya. Edición de los talleres realizados durante el curso 2003-2004 en el Laboratorio de técnicas y paisajes contemporáneos de la Escuela Técnica Superior de Arquitectura de Madrid
- Beck, J (2011) Concrete ambivalence: inside the bunker complex. Cultural Politics, vol. 7.1, p. 83

- Cocroft, W. y Schofield, J. (ed.) (2009) A fearsome heritage: diverse legacies of the Cold War. Walnut Creek: Left Coast Press

- Diller, E. y Scofidio, R. (1994) Introduction. En: Diller, E. y Scofidio, R. (ed.) Back to the front: Tourisms of war. sl: FRAC Basse-Normandie: Princeton Architecural Press, p. 28

- Dolff-Bonekämper, G. (2001) Sites of memory and sites of discord: Historic monuments as a medium for discussing conflict in Europe. En: Forward planning: the function of cultural heritage in a changing Europe. Consejo de Europa

- Van den Abbeele, G. (1994) Armoredsights / sites blindés. En: Diller, E. y Scofidio, R. (ed.) Back to the front: Tourisms of war. sl: FRAC Basse-Normandie: Princeton Architecural Press, pp. 235-236

- Virilio, P. (1994) Bunker Archeology. Nueva York: Princeton Architectural Press

- Virilio, P. y Lotringer, S. (2003) Amanecer crepuscular. Buenos Aires: Fondo de Cultura Económica 